\title{
Natural rubber-based cushion gum compound formulation at various type and dosage of rubber processing oil and tackifier resin
}

\author{
Santi Puspitasari ${ }^{1 *}$, Norma Arisanti Kinasih ${ }^{1}$, Arief Ramadhan ${ }^{1}$, Adi Cifriadi ${ }^{1}$, Mochamad \\ Chalid $^{2}$ \\ ${ }^{1}$ Indonesian Rubber Research Institute, Jalan Salak Nomor 1, Bogor 16128, Indonesia \\ ${ }^{2}$ Faculty of Technology - University of Indonesia, Depok 16242, Indonesia \\ *Corresponding author. Tel. +62 $2518317819 / 8324047$ \\ E-mail: puspitasari.santi@puslitkaret.co.id
}

Submitted: 5 October 2020

Revised: 1 October 2021

Accepted: 14 October 2021

\begin{abstract}
Cold retreading technique dominates retreaded tire manufacturing process. The technique applies rubber cushion gum compound as adhesion medium to bond new tread with a worn old tire. High-quality cushion gum compound mainly requires good adhesive strength. Tackiness of the rubber compound can be improved by addition of tackifier resin and rubber processing oil (RPO). The research was aimed to evaluate the performance of various types and dosages of tackifier resin and bio-based RPO to physic-mechanical properties of cushion gum. A method in the manufacture of natural rubber-based cushion gum compound was in accordance with ASTM D3182. Cushion gum rubber compound formula was designed by using bio-based RPO such as pine tar oil at 5 and 12 phr and three types of tackifier resin such as rosin resin, phenolic resin, and hydrocarbon resin at 3 and 7 phr. Petroleumbased RPO and commercial cushion gum were selected as reference material. Curing characteristic and physicmechanical properties test results were used as a reference to determine cushion gum quality. The observation during experiment indicated that natural rubber-based cushion gum compound formulated with addition of 5 phr rosin resin and $5 \mathrm{phr}$ pine tar oil (code $\mathrm{ZH} 4$ ) has the closest curing characteristic and physic-mechanical properties to commercial cushion gum.
\end{abstract}

Keywords: adhesive, cushion gum, rubber processing oil, tackifier resin, tire retreading.

\section{INTRODUCTION}

The global tire market segment can be categorized into original equipment manufacturer (OEM) and replacement segments. Replacement of used tire with the new ones will generate hazardous waste to the environment due to their complex structure and varied composition (Niza et al., 2014; Thomas \& Gupta, 2016). Tire retreading technology offers an alternate solution that concerns to this issue. Retreading is well-known as beneficial process in the terms of economy and environment in an effort to extend service life of tire (Sasikumar et al., 2010; Simic \& DabicOstojic, 2016). It is a technological process in which a used tire's tread is removed and a new tread is positioned on the undamaged tire casing (Banerjee, 2019). In Indonesia, tire retreading industry plays important role in promoting the national downstream rubber agro-industry. The market share of tire retreading industry attains about $25 \%$ of total natural rubber domestic consumption (Dewan Karet Indonesia, 2018). Therefore, by strengthening tire retreading industry by means of providing good quality material needed for retreading tire manufacturing, it is believed can support especially the performance of the micro-scale tire retreading industry in preparation for the implementation of retread tire Good Manufacturing Practice programmed by the Ministry of Industry of the Republic Indonesia.

Commonly, it is known that two tire retreading techniques are being applied, cold and hot cure. Cold cure retreading is the process used for tires of commercial vehicles. It is applied by $80 \%$ of 
retreading manufacturer (Abdul-Kader \& Haque, 2011). While, hot retreading process is suitable for passenger vehicles. Cold cure has advantages as can be repeated several times because it does not influence on the structure of a retreaded tire (Dabic-Ostojic et al., 2014). Cold cure is done by setting up a new tread on a prepared tire in the form of ring or strip, and then such a tire is placed in autoclave where the pasting procedure of a new tread is done. Application of moulded and cured new tread to the outer surface of the tire is facilitated by cushion gum (Abdul-Kader \& Haque, 2011).

Cushion gum is a thin intermediate rubber compound layer that is applied on the casing outer surface to bond the pre-cured tread as adhesion medium (Ayres et al., 1997). The primary requirement of a cushion gum is to have good adhesive strength and a fast cure mechanism in order to improve the bonding of the new tread with the worn old tire (Banerjee, 2019). Highquality cushion gum will contribute on safe riding. It prevents new tread damage. Basak et al. (2012) stated that the tack of rubber compounds depends on various factors such as polymer characteristiclike structure and molecular weight, type and amount of rubber chemicals used, mainly fillers, tackifiers, plasticizers or rubber processing oil (RPO).

The content of plasticizers also affect the viscoelastic property of rubber (Oh et al., 2014). A special type of plasticizer can build tack or autohesion. Pine tar oil is regarded as alternative bio-based RPO which can improve tackiness into rubber compound to substitute conventional petroleum-based RPO such as paraffinic oil and aromatic oil (Ciesielski, 1999). Aromatic oils have substantially toxic potential due to the presence of polycyclic aromatic hydrocarbons (PAH) content (Oter et al., 2011). In accordance to carcinogenic property of aromatic oil, researcher are intensively investigate natural source of bio-based RPO.

Tackifier resin is added to rubber compound to create tackiness between the layers of the rubber compound during the processing stage (Ramcharan, 2014). In general, the tackifier used in rubber compound formulation can be generated from synthetic material such as hydrocarbon resin, coumarone-indene resin, allyl phenol/ formaldehyde condensate, or natural source as rosin and gums (Basak et al., 2012). Rosin resin in combination with pine tar oil is biodegradable bio-based rubber chemical that can be used to develop promising green rubber product. The research aimed to investigate the experimental performance of natural rubber-based cushion gum compound formulated with tackifier resin and bio-based RPO. The combination of various types and dosages of tackifier resin and bio-based RPO were found to promote anchoring of good quality cushion gum for retreading tire process.

\section{MATERIALS AND METHODS}

High-grade natural rubber type such as Ribbed Smoke Sheet (RSS) 1 was used as an elastomer. RSS 1 was provided by The Indonesian Rubber

Table 1. Cushion gum rubber formulation at various type and dosage of RPO plasticizer.

\begin{tabular}{lrrrrrr}
\hline \multirow{2}{*}{ Materials } & \multicolumn{7}{c}{ Dosage (phr) } \\
\cline { 2 - 7 } & ZH 1 & \multicolumn{1}{c}{ ZH 2 } & \multicolumn{1}{c}{ ZH 4 } & ZH 5 & ZH 7 & \multicolumn{1}{c}{ ZH 8 } \\
\hline Natural rubber, RSS 1 & 100.0 & 100.0 & 100.0 & 100.0 & 100.0 & 100.0 \\
Zinc oxide & 5.0 & 5.0 & 5.0 & 5.0 & 5.0 & 5.0 \\
Stearic acid & 2.0 & 2.0 & 2.0 & 2.0 & 2.0 & 2.0 \\
TMQ & 2.0 & 2.0 & 2.0 & 2.0 & 2.0 & 2.0 \\
6PPD & 2.0 & 2.0 & 2.0 & 2.0 & 2.0 & 2.0 \\
Paraffin wax & 3.5 & 3.5 & 3.5 & 3.5 & 3.5 & 3.5 \\
Carbon Black N330 & 50.0 & 50.0 & 50.0 & 50.0 & 50.0 & 50.0 \\
CBS & 1.6 & 1.6 & 1.6 & 1.6 & 1.6 & 1.6 \\
Sulfur & 2.2 & 2.2 & 2.2 & 2.2 & 2.2 & 2.2 \\
Rosin resin & 5.0 & 5.0 & 5.0 & 5.0 & 5.0 & 5.0 \\
Paraffinic oil & 5.0 & 12.0 & - & - & - & - \\
Pine Tar Oil & - & - & 5.0 & 12.0 & - & - \\
Aromatic Oil & - & - & - & - & 5.0 & 12.0 \\
\hline
\end{tabular}


Table 2. Cushion gum rubber formulation at various type and dosage of resin tackifier.

\begin{tabular}{lrrrrrr}
\hline \multirow{2}{*}{ Materials } & \multicolumn{7}{c}{ Dosage $(\mathrm{phr})$} \\
\cline { 2 - 7 } & \multicolumn{1}{c}{ NT 1 } & \multicolumn{1}{c}{ NT 3 } & NT 4 & NT 6 & NT 7 & NT 9 \\
\hline Natural rubber, RSS & 100.0 & 100.0 & 100.0 & 100.0 & 100.0 & 100.0 \\
Zinc oxide & 5.0 & 5.0 & 5.0 & 5.0 & 5.0 & 5.0 \\
Stearic acid & 2.0 & 2.0 & 2.0 & 2.0 & 2.0 & 2.0 \\
TMQ & 2.0 & 2.0 & 2.0 & 2.0 & 2.0 & 2.0 \\
6PPD & 2.0 & 2.0 & 2.0 & 2.0 & 2.0 & 2.0 \\
Paraffin wax & 3.5 & 3.5 & 3.5 & 3.5 & 3.5 & 3.5 \\
Carbon Black N 330 & 50.0 & 50.0 & 50.0 & 50.0 & 50.0 & 50.0 \\
CBS & 1.6 & 1.6 & 1.6 & 1.6 & 1.6 & 1.6 \\
Sulfur & 2.2 & 2.2 & 2.2 & 2.2 & 2.2 & 2.2 \\
Pine Tar Oil & 12.0 & 12.0 & 12.0 & 12.0 & 12.0 & 12.0 \\
Rosin resin & 3.0 & 7.0 & - & - & - & - \\
Phenolic resin & - & - & 3.0 & 7.0 & - & - \\
Hydrocarbon resin & - & - & - & - & 3.0 & 7.0 \\
\hline
\end{tabular}

Research Institute. Thus, rubber chemicals that were involved in the manufacture of cushion gum consisted as an activator (zinc oxide and stearic acid), antioxidant (2,2,4-Trimethyl-1,2dihydroquinoline, and $\mathrm{N}-(1,3-$ dimethylbutyl)$\mathrm{N}$ '-phenyl-p-phenylenediamine, 6PPD), antiozonant (paraffin wax), reinforcing filler (carbon black N330), accelerator (N-Cyclohexyl-2benzothiazole sulfenamide CBS), vulcanizing agent (sulfur), tackifier resin, and rubber processing oil (RPO). Resin was used in the experiment consisted of rosin resin, phenolic resin, and hydrocarbon resin. While, RPO which was functioned as a plasticizer consisted of petroleumbased RPO, such as aromatic oil and paraffinic oil, and bio-based RPO, such as pine tar oil. All of the rubber compounds ingredients were industrial grade and used without further purification. The rubber chemicals except RPO were purchased from PT Multi Citra Chemindonusa. Meanwhile, the RPO was supplied by PT Organik Inti Indonesia. Rubber compound formulas for natural rubber-based cushion gum were designed as given in Table 1 and Table 2 for various types and dosages of RPO and tackifier resin, respectively. The dosage of RPO was arranged as 5 and 12 per hundred rubber (phr), while the dosage of resin was 3 and $7 \mathrm{phr}$. Furthermore, the rubber compound formulation which was designed by combining $5 \mathrm{phr}$ of rosin resin and $12 \mathrm{phr}$ pine tar oil was already presented in the previous publication (Puspitasari et al., 2020). Thus, in the research, this formula (5 phr of rosin resin and 12 phr of pine tar oil) was used as a comparison for other rubber compound formulations that were designed in this research.

The experiment was conducted at a laboratory scale by using two rolled open mill model Berstorf. The rubber compounding procedure was in accordance with ASTM D3182 (ASTM, 2016). Firstly, RSS1 was masticated and milled into softened mass in order to facilitate the mixing of rubber and chemicals. Rubber chemicals were added into softened rubber by the following order tackifier resin, activator, antioxidant, antiozonant, filler, RPO plasticizer, accelerator, and vulcanizing agent, respectively. Rubber mixture was blended and re-milled into homogenized rubber cushion gum compound. The rubber compound was matured for at least 24 hours at room temperature. Homogenized rubber cushion gum was taken for around $50 \mathrm{~g}$ as a curing characteristic sample. Curing time was analyzed by using Moving Die Rheometer (MDR) Alpha 2000R by Alpha Technologies. The result of curing time as optimum curing time $\left(\mathrm{tc}_{90}\right)$ was defined as the time for the rubber cushion gum curing process at 150 ${ }^{\circ} \mathrm{C}$.

Cured rubber cushion gum (vulcanizate) was tested the physic-mechanical properties, referred to the following parameters hardness, tensile strength, elongation at breaks, and adhesive strength. Hardness testing procedure referred to ASTM D2240-05 (ASTM, 2010) was performed by Frank Durometer Shore A. Universal Testing Machine (UTM) 2000R Llyod Tensometer was used to evaluate the tensile properties in accordance to ASTM D412-06ae2 (ASTM, 2013). 


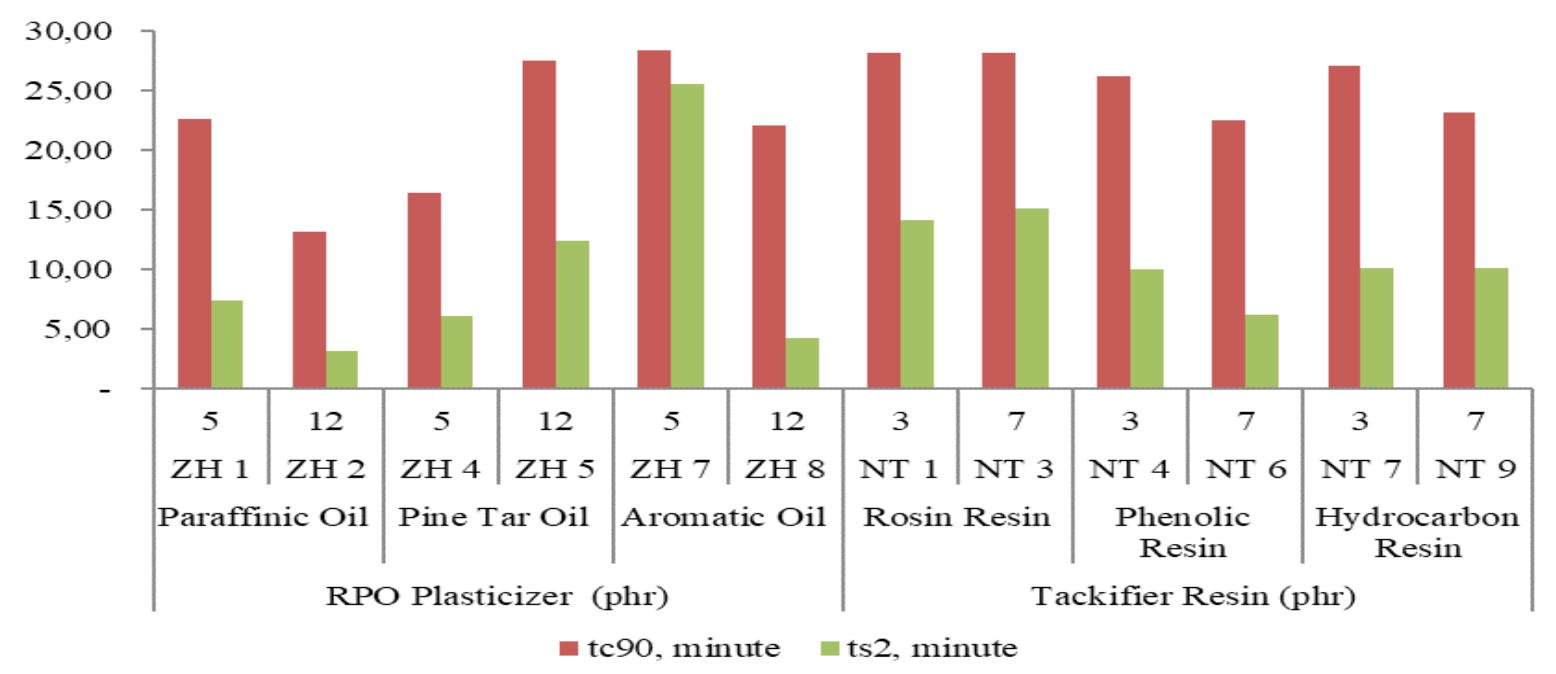

Figure 1. Curing characteristic of cushion gum compound.

The tensometer was operated at $500 \pm 50 \mathrm{~mm} /$ minute crosshead speed. The sample specimen was shaped as dumbells with a thickness of $2 \mathrm{~mm}$, and the test was repeated three times for each tensile test parameter. The adhesive strength of cushion gum was measured by using UTM INSTRON in accordance with ASTM D413-98 (ASTM, 2017). The result of the physic-mechanical properties was evaluated to determine the most optimum cushion gum compound formula.

\section{RESULTS AND DISCUSSION}

Oh et al. (2014) proposed that the curing curve can be used to describe the microstructural characteristic of cured rubber compound. Several important parameters are extracted such as torque $(\mathrm{M})$, scorch time $\left(\mathrm{ts}_{2}\right)$, and optimum cure time $\left(\mathrm{tc}_{90}\right)$. In the research, curing characteristics was analyzed in regards to $\mathrm{ts}_{2}$ and $\mathrm{tc}_{90}$. Scroch time gives an indication about the duration needed until the cross-linking process starts (Bergmann \& Trimbach, 2014). While, $\mathrm{tc}_{90}$ is illustrated as the time required for reaching $90 \%$ of maximum torque (Khimi \& Pickering, 2014). Both parameters are regarded as the main requirement during the application of cushion gum on retreading tire manufacturing process. Short $\mathrm{tc}_{90}$ will be followed with short moulding time and high manufacturing efficiency, which can also reduce energy consumption (Xu et al., 2020). High amount of heat energy during tire production is consumed during the vulcanization process

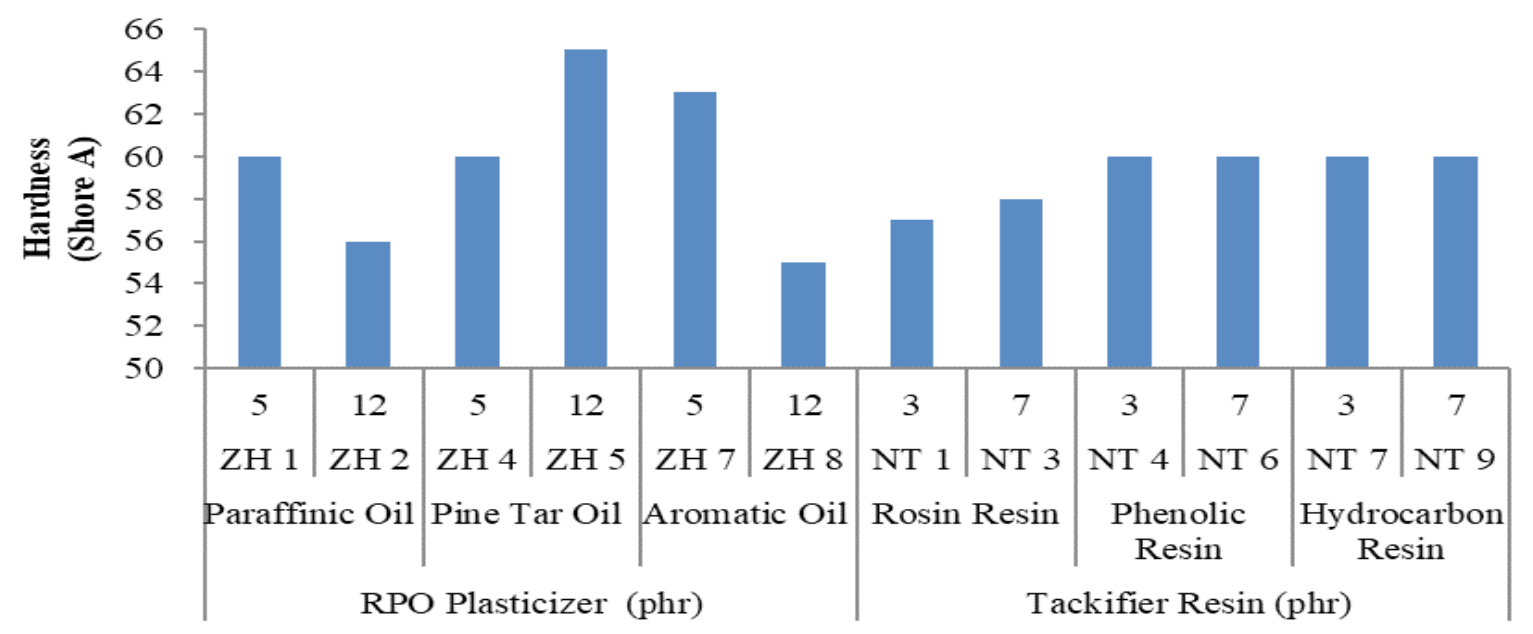

Figure 2. Hardness test result of cushion gum vulcanizate. 


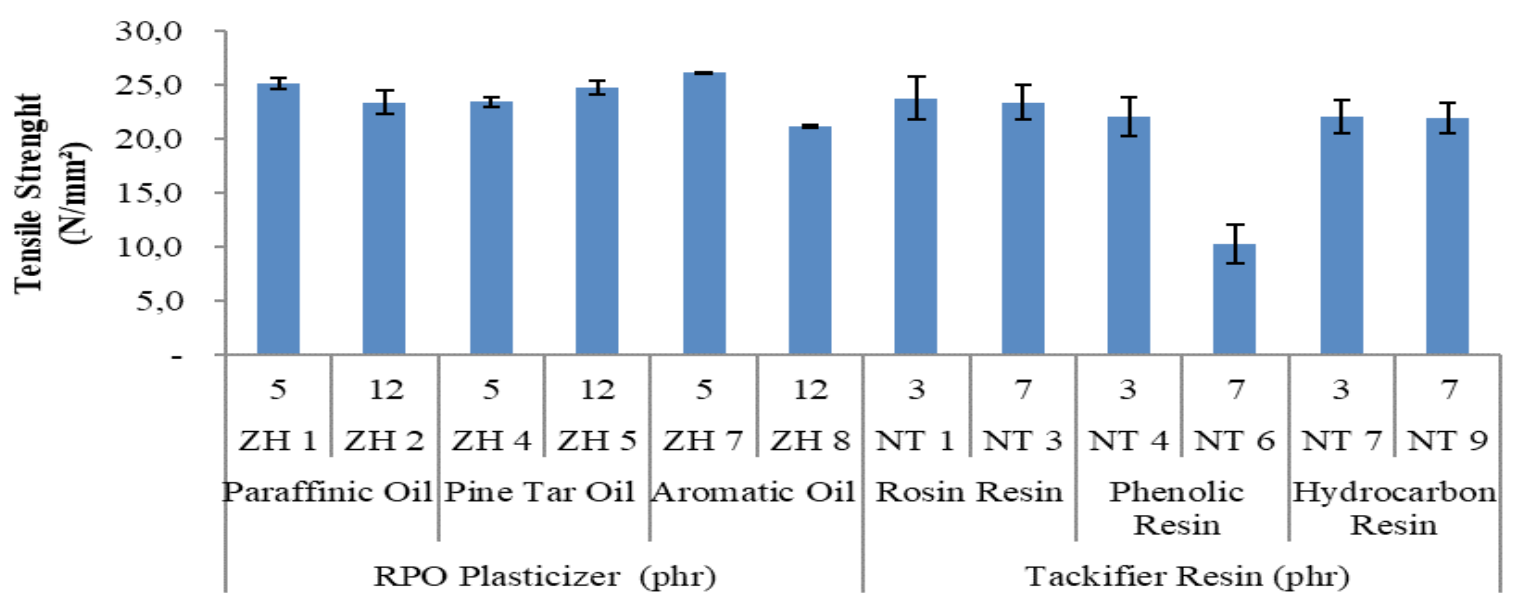

Figure 3. Tensile strength test result of cushion gum vulcanizate.

(Zhang et al., 2019). On the contrary, longer ts $\mathrm{s}_{2}$ is preferred since it enables the safer processing of rubber compounds (Formela et al., 2015). Figure 1 illustrates $\mathrm{ts}_{2}$ and $\mathrm{tc}_{90}$ values of each rubber cushion gum compound.

Figure 1 indicates that RPO evidently influenced $\mathrm{ts}_{2}$ and $\mathrm{tc}_{90}$ of rubber cushion gum compound than tackifier resin. Values of $\mathrm{ts}_{2}$ and $\mathrm{tc}_{90}$ on the variation of tackifier resin content were relatively stable due to higher loading. This result was in line with research findings by Pajarito (2015), which stated that the curing characteristic of rubber compounds was a function of ingredient loading. RPO to be the main ingredient affecting the curing of the natural rubber compound, followed by vulcanizing agent and accelerator. At the same tackifier resin dosage, increasing of petroleumbased RPO plasticizer resulted reduction of $\mathrm{ts}_{2}$ and $\mathrm{tc}_{90}$. Petroleum-based RPO consists of aromatic compound (Mohamed et al., 2013). Increasing on aromaticity content of petroleum-based RPO plasticizer caused a significant reduction on $\mathrm{ts}_{2}$ time as confirmed by addition of $5 \mathrm{phr}$ to $12 \mathrm{phr}$ of aromatic oil. The composition of aromatic content in aromatic oil is in the range of $70 \%$. This aromatic content is compatible with semi polar and polar polymer (Pakhathirathien et al., 2016). Higher compatibility caused higher plasticization effect.

On the other hand, more pine tar oil contained in natural rubber-based cushion gum compound induced raise on $\mathrm{ts}_{2}$ and $\mathrm{tc}_{90}$ values. Longer $\mathrm{ts}_{2}$ and $\mathrm{tc}_{90}$ might due to the high acid compound contained in pine tar inhibiting the curing mechanism of NR. The chemical composition of pine tar oil is extremely complex, containing aromatic hydrocarbon, tar acid, and tar bases (Braun-Falco et al., 1991). Acidic constituents such as tricyclic

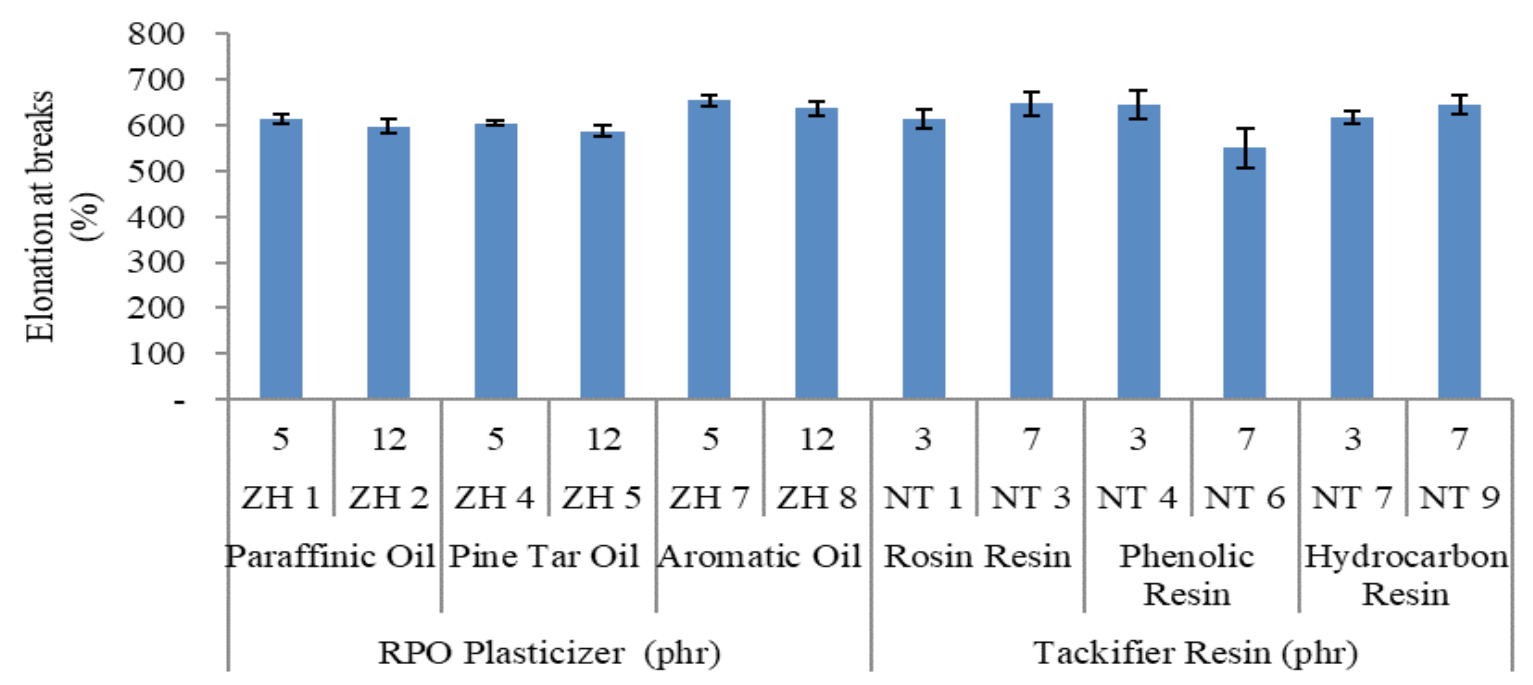

Figure 4. Elongation at breaks test result of cushion gum vulcanizate. 


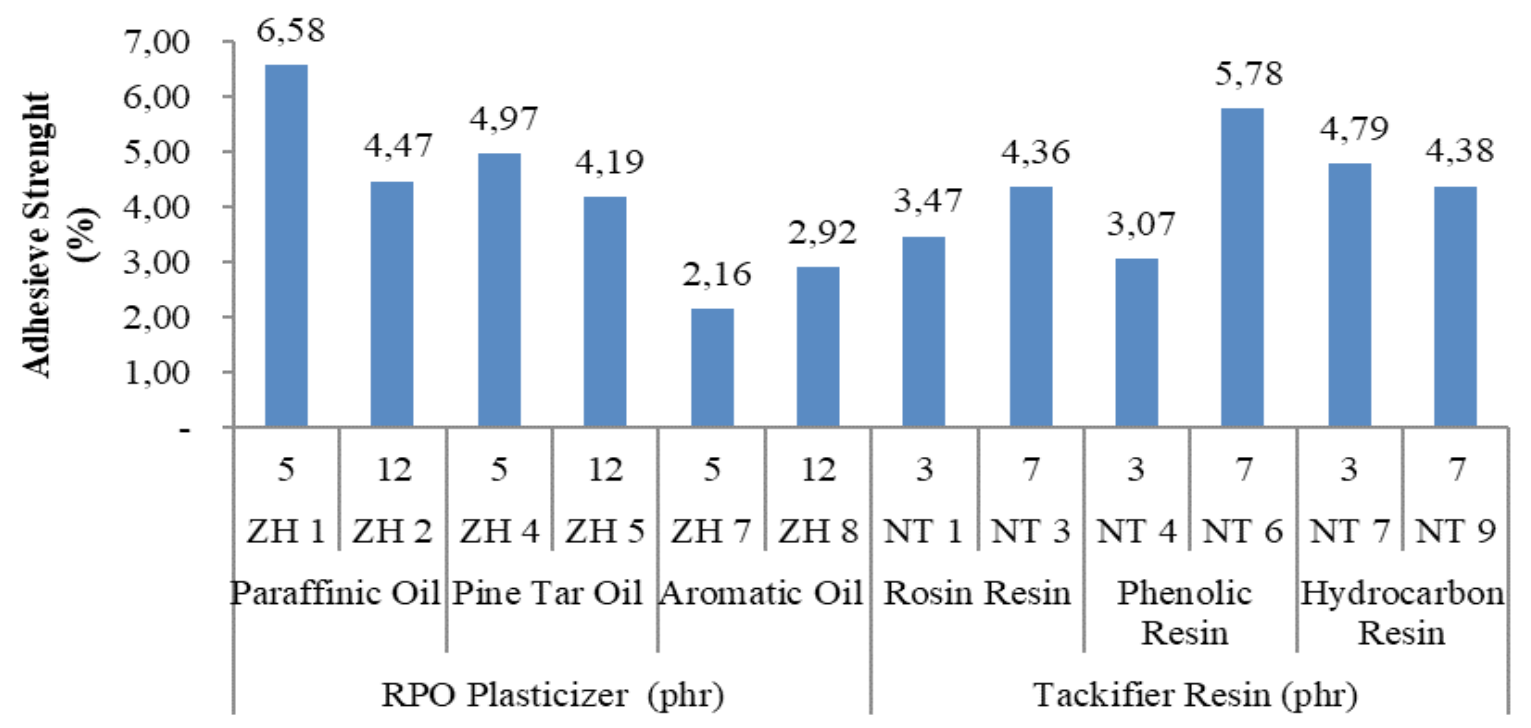

Figure 5. Adhesive strength test result of cushion gum vulcanizate.

diterpenoid resin acids, fatty acids, and phenolic compounds (Ahmed et al., 2017). The higher content of rosin resin has no effect to curing time $\left(\mathrm{ts}_{2}\right.$ and $\mathrm{tc}_{90}$ ) of rubber cushion gum compound. In the case of the usage of phenolic resin and hydrocarbon resin, it shows a tendency on the acceleration of $\mathrm{ts}_{2}$ and $\mathrm{tc}_{90}$ at higher resin loading. The addition of $12 \mathrm{phr}$ of pine tar oil (ZH5) and 5 phr (ZH7) of aromatic oil at $5 \mathrm{phr}$ rosin resin gave slightly better processing safety ie longer scorch time that other dosages or types of RPO plasticizer. However, due to its toxicology property, aromatic oil is not further recommended. Furthermore, 12 phr of pine tar oil with addition of $3 \mathrm{phr}$ (NT1), 5 phr (ZH5), and $7 \mathrm{phr}$ (NT3) of rosin resin show the most stable curing time.

Hardness value of rubber cushion gum vulcanizate is given in Figure 2. From Figure 2, it is obviously seen that variation of RPO has a greater effect to the hardness value compared to tackifier resin. Rubber cushion gum vulcanizate hardness were remain constant almost in all types of tackifier resin. Except on rosin resin application, it showed slightly higher hardness at higher loadings. Increasing of conventional petrobased RPO plasticizer such as paraffinic oil and aromatic oil loading tend to reduce the hardness value of rubber cushion gum vulcanizate. The hardness decrease with an increasing quantity of petro-based RPO since the plasticizing and swelling effects were more effective (Syamin et al., 2017). The plasticization effect of petrobased RPO plasticizer at the carbon black/rubber interface corresponds to the compatibility of rubber with its RPO (Pechurai et al., 2015). The sharpest hardness reduction (up to 8 points) was shown by addition of aromatic oil since this type of extender oil has the highest compatibility to natural rubber. Otherwise, the higher content of pine tar oil precisely raised the hardness value. It was found that natural rubber-based cushion gum vulcanizate containing pine tar oil gave a higher hardness value up to 65 Shore A.

The elasticity properties of natural rubberbased cushion gum vulcanizates as a function of RPO and tackifier resin are plotted in Figure 3 and 4, respectively. Refer to Figure 3, it was found that RPO plasticizer which was produced from petroleum at $12 \mathrm{phr}$ resulted lower tensile strength, while pine tar oil at the same dosage slightly increases the tensile strength. It was indicated that pine tar oil had opposite performance to petroleumbased RPO plasticizer on tensile strength parameter. The high viscosity character of pine tar oil might contribute on increasing of tensile strength on rubber cushion gum vulcanizate. High viscosity is related to high molecular weight. Therefore the addition of high viscous pine tar inhibited natural rubber molecular chain mobility since it decreases the free volume of NR molecular structure. As same with petroleum-based RPO plasticizer, all types and dosages of tackifier resin also show a tendency reduction of tensile strength value. Tackifier resin could be functioned as a processing aid in the rubber industry by reducing rubber compound viscosity. A significant reduction of 
Table 3. Comparison of cushion gum quality.

\begin{tabular}{clrr}
\hline No & \multicolumn{1}{c}{ Parameter } & Commercial cushion gum & IRRI cushion gum \\
\hline 1 & Scorch time (minute) & 4.14 & 6.10 \\
2 & Optimum cure time (minute) & 13.69 & 16.43 \\
3 & Hardness, Shore A & 60.00 & 60.00 \\
4 & Tensile strength $\left(\mathrm{N} / \mathrm{mm}^{2}\right)$ & 25.40 & 23.40 \\
5 & Elongation at breaks $(\%)$ & 635.00 & 600.00 \\
6 & Adhesive strength $(\mathrm{kN} / \mathrm{m})$ & $\mathrm{NA}$ & 4.97 \\
\hline
\end{tabular}

tensile strength value was shown by the addition of $12 \mathrm{phr}$ aromatic oil (ZH8) and $7 \mathrm{phr}$ phenolic tackifier resin (NT6).

Commonly, reduction of tensile strength on natural rubber vulcanizate due to the high content of RPO addition was because of raise in chain mobility followed with reduction on the rubber viscosity. Easier natural rubber molecular chain movement indicated that the molecular interaction between natural rubber chains were decreased since the rubber molecules were further apart due to the rubber particle was in the swollen state (Syamin et al., 2017). When the rubber particle contact to the RPO molecule, it becomes swollen. The reduction of rubber molecular interaction was also responsible for the rising in elongation at breaks as illustrated in Figure 4. The lubricating effect of the RPO, besides increasing chain mobility, was also decrease the entanglement of the natural rubber chain molecules. Shorten natural rubber molecular chains participatied in reducing elongation at breaks (Pakhathirathien et al., 2016).

The primary function of tackifier resin is to improve the tackiness of the mixture especially for pressure-sensitive adhesive, but the presence of tackifier resin in rubber composite also slightly affected the physic-mechanical properties of the vulcanizate (Thaijaroen, 2011). Rubber viscosity and tack increased with tackifier resin content due to the concentration effect of tackifier resin and it was attributed to the wettability of substrate (Poh \& Ong, 2007). The adhesive strength of natural rubber-based cushion gum vulcanizates as a function of RPO and tackifier resin are plotted in Figure 5. Phenolic resin loading in rubber cushion gum compound has the strongest effect on rubber adhesive strength at the same dosage of pine tar oil as shown by addition of $7 \mathrm{phr}$ phenolic resin (NT6), but it has low tensile strength and elongation at breaks values. Thus, at the same level of tackifier resin, paraffinic oil and pine tar oil indicated better performance on rubber adhesiveness compared to aromatic oil. Better adhesive properties on rubber cushion gum vulcanizate containing pine tar oil since the oil is generally known as sticky materials and contains some resinous compound.

Referred to the analysis result which had been mentioned in Figure 5, natural rubberbased cushion gum with codification as $\mathrm{ZH} 4$ was regarded has the closest characteristic to commercial cushion gum. As summarized in Table 3, natural rubber-based cushion gum ZH4 has rather longer $t_{2}$ and $t c_{90}$, equal hardness, and lower tensile strength and elongation at breaks. This type of rubber cushion gum compound was formulated by the addition of $5 \mathrm{phr}$ rosin resin and 5 phr of pine tar oil.

\section{CONCLUSIONS}

The effect of RPO and tackifier resin on physicmechanical characteristic of natural rubber-based cushion gum compound were investigated in this experiment. It exhibited that RPO plasticizer was proved to have stronger effect to natural rubberbased cushion gum hardness, tensile strength, and elongation at breaks compared to tackifier resin. While on the adhesive strength property, between RPO and tackifier resin were regarded had an equal role. Referred to the quality of commercial cushion gum, rubber cushion gum formula coded with ZH4 which designed with addition of $5 \mathrm{phr}$ rosin resin and 5 phr pine tar oil was selected to be the most optimum formula in the laboratory scale production of cushion gum. This formula resulted cushion gum with longer scorch time which corresponds with higher processing safety, although it had slightly lower physic-mechanical properties compared to the commercial cushion gum.

In the research, the test parameters to evaluate the performance of the tackifier resin and RPO on cushion gum quality were still very limited, 
therefore in future research the physical property test can be improved with an additional parameter such as Modulus 300\%, tear strength, and density of the natural rubber-based cushion gum vulcanizate.

\section{ACKNOWLEDGEMENTS}

The Authors highly acknowledge to Ministry of Research and Technology (National Research and Innovation Board) for supporting financial research funding through INSINAS Program Year 2020 (Contract Number 24/INS-1/E4/2020). The Authors were also thank to Zahra Krishna Hadi and Novita Putri Wahyuni, College Student of STMI Polytechnic Jakarta for their technical assistance.

\section{REFERENCES}

Abdul-Kader, W., \& Haque, M. S. (2011). Sustainable tyre remanufacturing: an agent-based simulation modelling approach. International Journal of Sustainable Engineering, 4(4), 330-347. https:// doi.org/10.1080/19397038.2011.581392

Ahmed, S. A., Moren, T., Sehlstedt-Persson, M., \& Blom, A. (2017). Effect of oil impregnation on water repellency, dimensional stability and mold susceptibility of thermally modified European Aspen and downy birch wood. Journal of Wood Science, 63, 74-82. https://doi.org/10.1007/ s10086-016-1595-y

ASTM (American Society for Testing and Materials). (2010). ASTM D2240-05 Standard test method for rubber property - Durometer hardness. Pennsylvania: USA, ASTM.

ASTM (American Society for Testing and Materials). (2013). ASTM D412-06ae2 Standard test method for vulcanized rubber and thermolastic elastomers - Tension. Pennsylvania: USA, ASTM.

ASTM (American Society for Testing and Materials). (2016). ASTM D3182 Standard pratice for rubbermaterials, equipment, and procedures for mixing standard compounds and preparing standard vulcanized sheets. Pennsylvania: USA, ASTM.

ASTM (American Society for Testing and Materials). (2017). ASTM D413-98 Standard test method for rubber property - Adhesion to flexible substrate. Pennsylvania: USA, ASTM.

Ayres, R., Ferrer, G., \& Leynseele, T. V. (1997). Ecoefficiency, asset recovery and remanufacturing. European Management Journal, 15(5), 557-574. https://doi.org/10.1016/S0263-2373(97)00035-2

Banerjee, B. (2019). Tyre Retreading. Deutsch: CPI Books GmbH.

Basak, G. C., Bandyopadhyay, A., \& Bhowmick, A. K. (2012). The role of tackifiers on the auto-adhesion behaviour of EPDM rubber. Journal of Material
Science, 47, 3166-3176. https://doi.org/10.1007/ s10853-011-6151-y

Braun-Falco, O., Plewig, G., \& Wolff, H. H. (1991). Dermatology. Heidelberg: Springer-Verlag.

Bergmann, C., \& Trimbach, J. (2014). Influence of plasticizers on the properties of natural rubber based compound. KGK Rubberpoint, 67(7), 4049.

Ciesielski, A. (1999). An intoduction to rubber technology. UK: RAPRA Technology Ltd.

Dabic-Ostojic, S., Miljus, M., Bojovic, N., Glisovic, N., \& Milenkovic, M. (2014). Applying a mathematical approach to improve the tire retreading process. Resources, Conservation and Recycling, 86, 107-117. https://doi.org/10.1016/j. resconrec.2014.02.007

Dewan Karet Indonesia. (2018). Data industri karet 2018. Jakarta, Indonesia: Dekarindo.

Formela, K., Wasowicz, D., Formela, M., Hejna, A., \& Haponiuk, J. (2015). Curing characteristics, mechanical and thermal properties of reclaimed ground tire rubber cured with various vulcanizing systems. Iranian Polymer Journal, 24, 289-297. https://doi.org/10.1007/s13726-015-0320-9

Khimi, S. R., \& Pickering, K. L. (2014). A new method to predict optimum cure time of rubber compound using dynamic mechanical analysis. Journal of Applied Polymer Science, 131(6), 40008. https:// doi.org/10.1002/app.40008

Mohamed, R., Zain, N. W., Shafie, N. A., \& Norizan, M. N. (2013). Aromatic and epoxidised oil curing and rebound resilience characteristic and their humidity effect of hardness on NR vulcanizates. Advanced Materials Research, 812, 138-144. https://doi.org/10.4028/www.scientific.net/ AMR.812.138

Niza, S., Santos, E., Costa, L., Ribeiro, P., \& Ferrao, P. (2014). Extended producer responsibility policy in Portugal: a strategy towards improving waste management performance. Journal of Cleaner Production, 117(1), 277-287. https://doi. org/10.1016/j.jclepro.2013.07.037

Oh, J., Yoo, Y. H., Yoo, I. S., Huh, Y. I., Chaki, T. K., \& Nah, C. (2014). Effect of plasticizer and curing system on freezing resistance of rubbers. Journal of Applied Polymer Science, 131, 39795. https:// doi.org/10.1002/app.39795

Oter, M., Karaagac, B., \& Deniz, V. (2011). Substitution of aromatic processing oils in rubber compounds. KGK Rubberpont, 64(9), 48-51.

Pajarito, B. (2015). Effect of ingredient loading on vulcanization characteristic of a natural rubber compound. Advanced Material Research, 1125, 50-54. https://doi.org/10.4028/www.scientific. net/AMR.1125.50

Pakhathirathien, C., Pearuang, K., Rungvichanniwat, A., Kaesaman, A., \& Nakason, C. (2016). A 
comparative study of stearyl aromatic esters and aromatic oil as processing aids in natural rubber compounds. Songklanarin Journal of Science and Technology, 38(5), 501-506.

Pechurai, W., Chiangta, W., \& Tharuen, P. (2015). Effect of vegetable oils as processing aids in SBR compound. Macromolecular Symposia, 354, 191196. https://doi.org/10.1002/masy.201400079.

Poh, B. T., \& Ong, L. N. (2007). Adhesion properties of styrene-butadiene rubber (SBR)/Standard Malaysian Rubber (SMR-L) - based adhesieve in the presence of phenol formaldehyde resin. Express Polymer Letters, 1(10), 654-659. https:// doi.org/10.3144/expresspolymlett.2007.89

Puspitasari, S., Kinasih, N. A., Cifriadi, A., Ramadhan, A., Hadi, Z. K., Wahyuni, N. P., \& Chalid, M. (2020). Seleksi resin dan rubber processing oil (RPO) dalam pembuatan cushion gum sebagai perekat ban vulkanisir. Majalah Kulit, Karet, dan Plastik, 36(1), 9-16. https://doi.org/10.20543/ mkkp.v36i1.6105

Ramcharan. (2014). Product development information. Chennai, India: Ramcharan.

Sasikumar, P., Kannan, G., \& Haq, A. N. (2010). A multi-echelon reverse logistics network design for product recovery - a case of truck tire remanufacturing. International Journal of Advance Manufacturing Technology, 49, 12231234. https://doi.org/10.1007/s00170-009-2470-4

Simic, V., \& Dabic-Ostojic, S. (2016). Interval- parameter chance-constrained programming model for uncertainty-based decision making in tire retreading industry. Journal of Cleaner Production, 167, 1490-1498. https://doi. org/10.1016/j.jclepro.2016.10.122

Syamin, Y. M., Azemi, S., \& Dzarani, K. (2017). Evaluation of cooking oil as processing additive for natural rubber. ASEAN Journal of Science and Technology Development, 34(1), 17-25. https:// doi.org/10.29037/ajstd.71

Thaijaroen, W. (2011). Effect of tackifiers on mechanical and dynamic properties of carbon black filled NR vulcanizate. Polymer Engineering and Science, 51, 2465-2472. https://doi.org/10.1002/pen.22033

Thomas, B.S., \& Gupta, R.C. (2016). Properties of high strength concrete containing scrap tire rubber. Journal of Cleaner Production, 116(1), 86-92. https://doi.org/10.1016/j.jclepro.2015.11.019

Xu, H., Fan, T., Ye, N., Wu, W., Huang, D., Wang, D., Wang, Z., \& Zhang, L. (2020). Platicization effect of bio-based plasticizers from soybean oil for tire tread rubber. Polymers, 12, 623-632. https://doi. org/10.3390/polym 12030623

Zhang, J., Wang, B., Liu, X., Cheng, L., Yan, H., Ding, Q., Tan, J., \& Yang, W. (2019). Energy-saving performance and production accuracy of the direct-pressure tire curing technology with an expandable steel internal mold. Applied Science, 10, 79-93. https://doi.org/10.3390/app10010079 
